\title{
Nitriding of car engine parts using ZeroFlow method
}

\begin{abstract}
This article presents new method of controlled gas nitriding called ZeroFlow, which is used for nitriding of selected car engine parts. Parts such as crankshafts, camshafts, piston rings, poppet valve springs and discs, piston pins or nozzles for unit injectors was nitrided with ZeroFlow method so far. Through the use of simulation models it was possible to develop the specially dedicated process with specific parameters for each of this parts; it allows forming of nitrided layer with strictly expected properties: required phase structure with thicknesses of each zone occurs in it and required hardness distribution. Moreover, through the use of simulation models this layers were obtained in in the shortest possible time, which is connected with the lowest energy consumption; therefore, nitriding process using ZeroFlow method is both economical and environmentally friendly. This article will discuss the essence of controlled gas nitriding process, with an emphasis on the influence of process parameters on results of nitriding process. This information are the basis to understand the issue of the kinetics of nitrided layer growth, and as it follows - for its practical application in designing, regulation and control of nitriding processes using simulation models (simulator of the kinetics of nitrided layer growth). Designing of ZeroFlow nitriding processes on the basis of the kinetics of nitrided layer will be shown on the example of nitriding of crankshafts for sports car engines.
\end{abstract}

Key words: heat treatment, controlled gas nitriding, ZeroFlow method, nitrided layer, kinetics

\section{Introduction}

ZeroFlow is a new method of controlled gas nitriding, developed at the Poznan University of Technology, which enables precise forming of nitrided layers using nitriding kinetics. It is characterized by much lower consumption of gases, as well as simplification of the nitriding furnace and of the process itself, while full control over the kinetics of the growth of nitrided layer is still maintained. The same as in the traditional process, ZeroFlow method assumes the use of atmosphere consisting only raw ammonia. However, unlike to the traditional method, kinetics can be controlled by adjusting the chemical composition of the atmosphere in the furnace retort (by adjusting the nitriding potential) through the regulation of ammonia flow rate, or more precisely through the regulation of ammonia inflow rate by stopping and reactivating ammonia feeding into the furnace retort. It is significant that in ZeroFlow method ammonia inflow rate is temporarily reduced to zero, which makes much easier to control the chemical composition of the atmosphere. To sum up, using a unary atmosphere makes the ZeroFlow method simpler than currently popular methods based on binary atmospheres, but simultaneously it allows to control the kinetics of nitrided layer growth by regulating of ammonia inflow rate [4]. Until now, ZeroFlow nitriding method has been introduced in 26 industrial plants in Poland and many other countries worldwide, such as: Italy, Great Britain, Canada, Sweden, Singapore, South Korea, Germany, Czech Republic, Belarus, Russia, India, Pakistan, Switzerland. 36 industrial installations have been constructed and implemented so far, another 4 are launched. Several thousands of nitriding processes for various parts of machines and vehicles have been conducted with positive results, which is the best verification of this method rightness.

Gathered experience shows that ZeroFlow method enables forming of nitrided layers with respect to the required phase structure, zone thicknesses, and hardness distribution.
Through the use of phenomenological models layers are produced in the shortest possible time, which is connected with the lowest energy consumption. Mathematical models of the kinetics of nitrided layer growth additionally allow determining nitrided layer phase structure and thickness of each zone that occurs in it as a function of process parameters: time, temperature and nitriding potential of the atmosphere. Layer obtained this way doesn't need costly and time-consuming grinding of iron nitrides, which leads to lower consumption of energy and materials. Several times lower consumption of gases in comparison with its consumption in another currently used nitriding processes, and as a result - much lower emission of post-process gases, also indicates on economical and environmentally friendly character of ZeroFlow method.

Thus, ZeroFlow is a new, rapidly evolving method of controlled gas nitriding, which fits into currently prevalent trends in the world: minimization of raw materials and energy consumption, as well as minimization of the negative impact on the environment [4]. However, it should be noted that ZeroFlow method is only general technological and structural solution, which enables carrying out processes in different, strictly selected parameters, such as temperature, nitriding potential of the atmosphere, time, speed of heating, reduction of potential etc. Therefore, each element requires the development of specially dedicated process with specific parameters; this task is supported by simulation models, which considerably speed up the development of new processes $[2,6]$. It is also worth mentioned that simulations of heat treatment processes are a really important issue and they allow observing various phenomena, which usually are not perceived in industrial practice (sometimes even in experimental research). They can also be a part of regulation and control of the processes [3].

Forming of nitrided layers occurs on steels that are most commonly used in transport machines engineering, like 
vehicles and aircrafts, or in technological machines and tools (used for example for the wood industry) engineering; therefore, ZeroFlow nitriding is used for parts of machines and vehicles such as: toothed wheels for wind power plants, plates for casting glass bulbs for lamps, inlet sleeves with the pushing piston, used in molds for aluminum pressure die casting, etc. Also many processes were conducted for parts of car engines: crankshafts, camshafts, piston rings, poppet valve springs and discs, piston pins or nozzles for unit injectors. Aim of nitriding of this elements is to obtain layer with higher surface hardness, improved fatigue life and corrosion resistance, increased wear resistant and antigallic properties. According to that, this layer increase durability of nitrided parts, and as a result - durability of machines and vehicles.

\section{The essence of nitriding process}

Controlled gas nitriding ZeroFlow is carried out at a higher temperature (usually from range between $490{ }^{\circ} \mathrm{C}-590$ ${ }^{\circ} \mathrm{C}$ ), using an atmosphere consisting of ammonia. Because of the low durability of the molecules (at average nitriding temperatures ammonia is in unstable thermodynamic state) ammonia disintegrates after contact with a metal surface, according to the following catalytic reaction of dissociation:

$$
\mathrm{NH}_{3} \stackrel{\mathrm{Fe}}{\Leftrightarrow} \mathrm{N}+3 / 2 \mathrm{H}_{2}
$$

As a result of diffusion of atomic nitrogen into the steel surface, layer with different properties than original material (the material of the core) is formed. Its phase structure, zone thicknesses, and as a consequence - its properties - depend both on the type of the steel and the parameters of the nitriding process: temperature, nitriding potential of the atmosphere and time. As a nitriding potential of the atmosphere we can describe a ratio of partial pressure of the atmosphere active ingredients. Atomic nitrogen and hydrogen, obtained by dissociation of ammonia, tends to recombine into diatomic molecules as soon as possible, whereas nitrogen diffusion occurs only when it is in atomic state - this means that is necessary to feed fresh amount of ammonia continuously into the furnace retort in order to carry out the process. Therefore, atmosphere in furnace retort during the process consist of nitriding gas $\mathrm{NH}_{3}$ and denitriding gas $\mathrm{H}_{2}$, which are the active ingredients of the atmosphere, and inert gas $\mathrm{N}_{2}[1,4$, 7]. According to this, we can describe nitriding potential of the atmosphere as a following formula:

$$
\mathrm{N}_{\mathrm{p}}=\frac{\mathrm{p}_{\mathrm{NH}_{3}}}{\left(\mathrm{p}_{\mathrm{H}_{2}}\right)^{3 / 2}}
$$

Depending on the activity of nitrogen in the atmosphere (which is connected with nitriding potential), nitriding of steel may be accompanied by growth of the single-, doubleor triple-phase layer $\left(\alpha, \gamma^{\prime}+\alpha, \varepsilon+\gamma^{\prime}+\alpha\right)$. The connection between phase structure and parameters such as nitriding potential and temperature is shown on $\mathrm{T}-\mathrm{N}_{\mathrm{p}}$ phase equi- librium diagram, also known as a Lehrer's diagram (Fig. $1)$. The boundaries of particular phases occurrence $(\alpha / \gamma$, $\left.\alpha / \gamma^{\prime}, \gamma / \varepsilon, \gamma^{\prime} / \varepsilon\right)$ are presented at this diagram as a function of temperature and nitriding potential. It is worth noting that the chemical potentials of nitrogen in particular phases at boundaries between them are equal, and at equilibrium conditions with atmosphere $\mathrm{NH}_{3}+\mathrm{H}_{2}$ they are equal to chemical potential of nitrogen in this atmosphere.

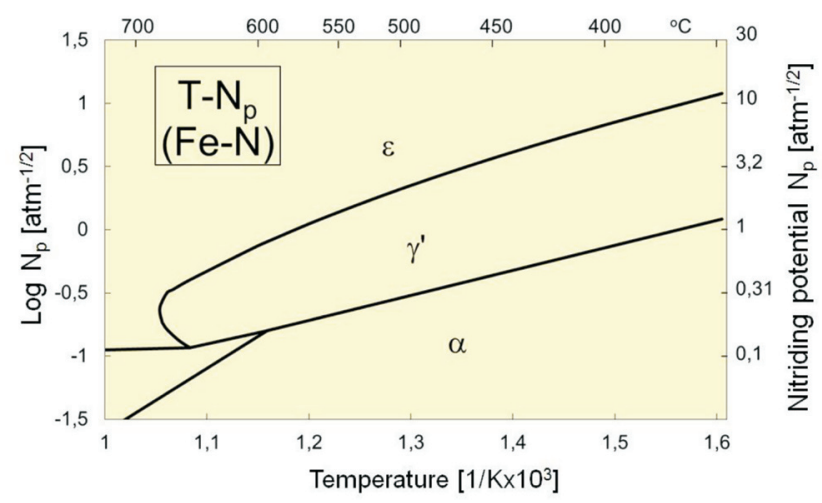

Fig. 1. $\mathrm{T}-\mathrm{N}_{\mathrm{p}}$ phase equilibrium diagram

We can conclude from Lehrer's diagram that depending on the nitriding potential of the atmosphere (if process temperature remains the same), nitrided layer obtained on iron and carbon steels can have one of these forms:

- single-phase structure $\alpha$ - at the nitriding potential $\mathrm{N}_{\mathrm{p}}^{\alpha}$, located in the graph on the range of $\alpha$ phase occurrence; - double-phase structure $\gamma^{\prime}+\alpha-$ at the nitriding potential $\mathrm{N}_{\mathrm{p}} \gamma^{\prime}$, located in the graph on the range of $\gamma^{\prime}$ phase occurrence;

- triple-phase structure $\varepsilon+\gamma^{\prime}+\alpha$ - at the nitriding potential $\mathrm{N}_{\mathrm{p}}^{\varepsilon}$, located in the graph on the range of $\varepsilon$ phase occurrence.

As far as Lehrer's diagram predicts in some measure phase structure of the nitrided layer, it doesn't deliver any information about the concentration of nitrogen in $\alpha, \gamma$ ' and $\varepsilon$ phases as a function of temperature and nitriding potential, however, these data are the basis for description of the kinetics of nitrided layer growth. L. Małdziński, on the basis on his own analysis and research, had determined lines and curves of isoconcentration (constant values of nitrogen concentration) in $\mathrm{T}-\mathrm{N}_{\mathrm{p}}$ phase equilibrium diagram, which allowed for the development of a modified $\mathrm{T}-\mathrm{N}_{\mathrm{p}}-\mathrm{N}$ phase equilibrium diagram (Fig. 2). This diagram delivers essential information required to develop models of the kinetics of the nitrided layer growth, which lack was for a long time a major obstacle to the development of research and kinetic description of the growth of layer [3, 4].

On the basis of phase equilibrium diagram $\mathrm{T}-\mathrm{N}_{\mathrm{p}}-\mathrm{N}$ we cannot draw conclusions about kinetics (speed) of nitrided layer growth and each phase that occurs in it. Phase structure and particular zone thicknesses also depends on time of the process. The influence of time was taken into account in phenomenological models of the kinetics of nitrided layer growth on iron and alloy steels, developed by L. Małdziński and co-workers [4]. This models also take into account a total 
influence of carbon and alloy elements on diffusion flows of nitrogen atoms into $\varepsilon, \gamma$ ' and $\alpha$ phases, and as a result - on the speed of growth of these phases. It cannot be forgotten that $\mathrm{T}-\mathrm{N}_{\mathrm{p}}-\mathrm{N}$ phase equilibrium diagram concerns only raw iron, when in fact especially his alloys with carbon (carbon steels) and alloy elements (alloy steels) are nitrided. L. Małdziński proved that $\mathrm{T}-\mathrm{N}_{\mathrm{p}}-\mathrm{N}$ phase equilibrium diagram can be used only for steels containing $\mathrm{Cr}, \mathrm{Mn}, \mathrm{Mo}, \mathrm{V}$, because content of this elements doesn't change its shape [3,4].

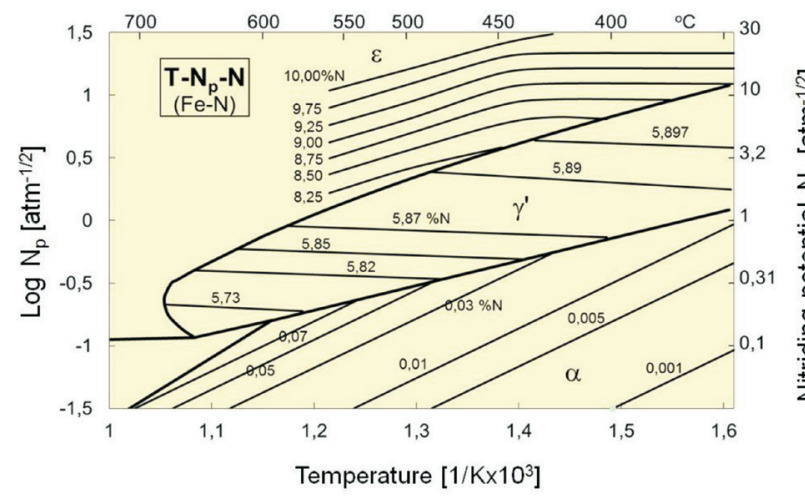

Fig. 2. $\mathrm{T}-\mathrm{N}_{\mathrm{p}}-\mathrm{N}$ phase equilibrium diagram

A large number of factors, which are relevant to nitriding process course, makes use of mathematical models necessary for precise forming of nitrided layers with respect to the required phase structure, zone thicknesses, and hardness distribution. Developed phenomenological models of the kinetics of nitrided layer thus can be applied in simulations of nitriding processes, where by adjusting the process parameters they enable forming phase structure of layer, i.e. types of particular phases and its thicknesses or surface concentrations and nitrogen concentration profiles in each phase. Furthermore, they allows to control growth of the $\varepsilon$ and $\gamma^{\prime}$ phases as a function of nitriding potential and temperature not only in simple single-stage processes, but also in more

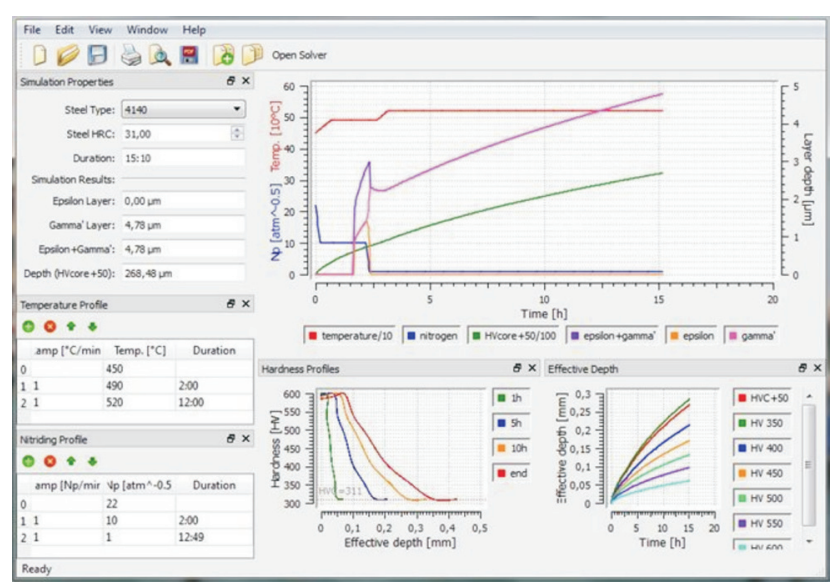

Fig. 3 Simulator of the kinetics of nitrided layer growth

complicated multi-stage processes. To sum up, these models enables determining kinetics of the nitrided layer growth as a function of process parameters: time, temperature and nitriding potential of the atmosphere. What is more, through the use of phenomenological models layers are produced in the shortest possible time, which is connected with the lowest energy consumption [4]. On the basis of mathematical models the simulator of the kinetics of nitrided layer has been developed by L. Małdziński. Simulator is an application that supports designing new processes of nitriding using ZeroFlow method; it allows to predict graphical and computational the growth of the nitrided layer thickness and each phase that occurs in it as a function of process parameters: time, temperature and nitriding potential of the atmosphere [5]. The further part of this article shows the example of designing nitriding process using models (simulator) of the kinetics of nitrided layer growth.

\section{Designing of the nitriding process on the basis of nitriding of crankshafts for sports car engines}

Technology of nitriding using ZeroFlow method has been developed, among others, for crankshafts assembled in sports car engines. The main purpose of nitriding of crankshafts is to obtain high surface hardness of journals and it concerns to carbon steels of higher quality or alloy steels. Discussed crankshafts were made of nickel-chromium-molybdenum steel 4340 (40HNMA according to PN), intended for hardening and tempering, consisting $0.37-0.44 \% \mathrm{C}, 0.5-0.8 \% \mathrm{Mn}$, $0.17-0.37 \% \mathrm{Si}, 0.6-0.9 \% \mathrm{Cr}, 1.25-1.65 \% \mathrm{Ni}, 0.15-0.25 \%$ Mo, $\max 0.03 \% \mathrm{P}, \max 0.025 \% \mathrm{~S}$ and $\max 0.3 \% \mathrm{Cu}$. Due to its application and working conditions, requirements for treated parts were set high, regarding nitrided layer phase structure, thickness of layer zones, thickness of effective precipitate zone, hardness, as well as dimensional and geometrical changes. Major requirements connected with nitriding process and nitrided layer included:

- a 5-6 $\mu \mathrm{m}$ thick compound zone $\varepsilon+\gamma^{\prime}$ (white layer);

- layer effective thickness with core hardness of $+50 \mathrm{HV}$ $(\mathrm{HVC}+50)$ at $\mathrm{gr}_{50}=0.4 \mathrm{~mm}$ (it should be noted that core hardness was $350 \mathrm{HV})$;

- precipitation zone effective thickness with hardness 600 $\mathrm{HV}$ at $\mathrm{g}_{600}=0.15 \mathrm{~mm}$;

- surface hardness of approximately $63 \mathrm{HRC}$.

With the aim of determining the process parameters, which ensure obtaining values written above, the number of simulations using models of the kinetics of nitrided layer growth had been carried out. On the basis of gathered experience, the double-stage process due to temperature was taken into consideration: $490{ }^{\circ} \mathrm{C}$ at I stage and $530{ }^{\circ} \mathrm{C}$ at II stage. As the simulation of the growth of effective depth case shows (Fig. 4), required effective case depth with hardness $\mathrm{HV} 400$ ( $\mathrm{HV} 400$ is equal to core hardness of $+50 \mathrm{HV}$ ) is obtained in layer after approximately 29 hours of nitriding (I stage $/ 490^{\circ} \mathrm{C} / 2 \mathrm{~h}$, II stage $/ 530{ }^{\circ} \mathrm{C} / 27 \mathrm{~h}$ ).

In next step the nitriding potential of the atmosphere $\mathrm{Np}$ was selected to obtain the required compound zone ( $\varepsilon$ $+\gamma^{\prime}$ ) thickness -5 to $6 \mu \mathrm{m}-$ in 29 hours (Fig. 5). First, at I stage of process the potential had been set on $\mathrm{NpI}=25$, which resulted in rapid growth of $\varepsilon+\gamma^{\prime}$ phase. Then in II stage potential was lowered to $\mathrm{NpII}=0.6$ to stop further 
unwanted growth of the iron nitrides; simultaneously the $\varepsilon$ phase was significantly reduced. In the beginning $\gamma^{\prime}$ phase was also slightly reduced, but after a few hours it started to increase again (this phenomenon is related to the gradient of the surface concentration of nitrogen $\mathrm{cN}$ on the boundaries of particular phases and - connected with this - flow of nitrogen atoms JN [2]). To avoid this, the nitrogen potential was lowered once more to $\mathrm{NpIII}=0.4$, which resulted in another reduction of $\gamma^{\prime}$ phase and finally - in inhibition of its further growth.

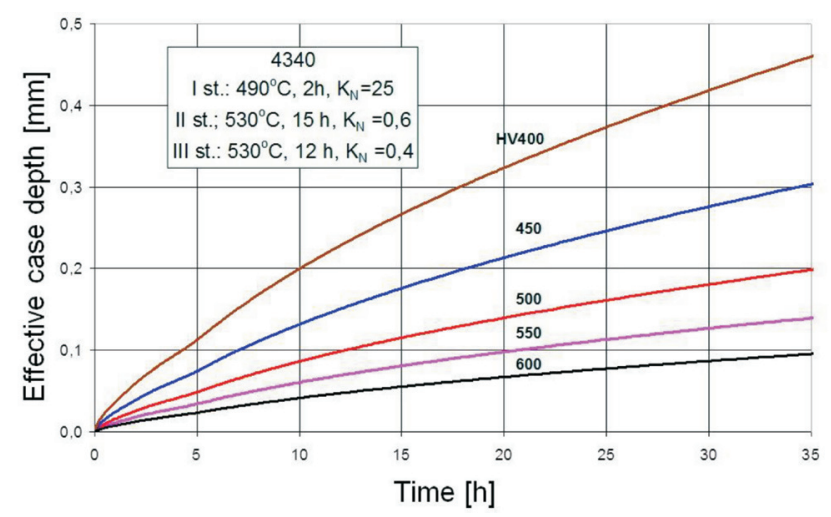

Fig. 4. Growth of effective depth case on 4340 steel

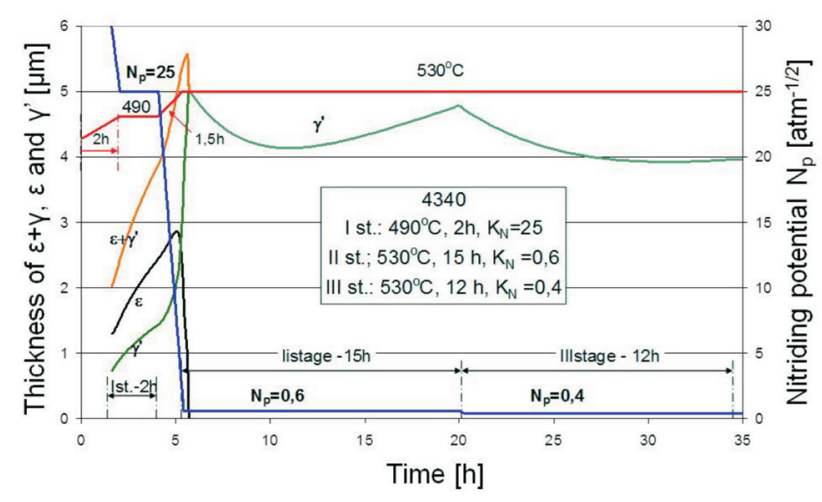

Fig. 5. Growth of compound zone (white layer) on 4340 steel

Table .1. Parameters of nitriding process for crankshafts for sport car engines using ZeroFlow method

\begin{tabular}{|c|c|c|c|}
\hline \multirow{2}{*}{ Stage } & Temperature & Time & Potential \\
\cline { 2 - 4 } & $\mathrm{T}\left[{ }^{\circ} \mathrm{C}\right]$ & $\mathrm{t}[\mathrm{h}]$ & $\mathrm{N}_{\mathrm{p}}\left[\mathrm{atm}^{-1 / 2}\right]$ \\
\hline 1 & 490 & 2 & 25 \\
\hline 2 & 530 & 15 & 0.6 \\
\hline 3 & 530 & 12 & 0.4 \\
\hline
\end{tabular}

Thus on the basis of simulation was developed the nitriding process with the parameters shown in the Tab. 1; this process was applied to crankshafts and specimens for metallographic examination. Metallographic examination carried out after the process shows that compound zone thickness is 5.7-6.2 $\mu \mathrm{m}$ (Fig. 6), and the effective case depth HV 400 is about $0.4 \mathrm{~mm}$ (Fig. 6), which is also shown at the graph of hardness distribution (Fig. 7). Moreover, the graph of hardness distribution shows that the effective case depth HV 600 is about $0.16 \mathrm{~mm}$, which means that actual results of nitriding process are consistent with expectations and all requirements have been fulfilled. To prevent deformation of crankshaft, it was treated in a special fixture in a vertical position. Also furnace heating and cooling time were extended, resulting in only a small amount of deformation, which did not exceed the allowed deviations.
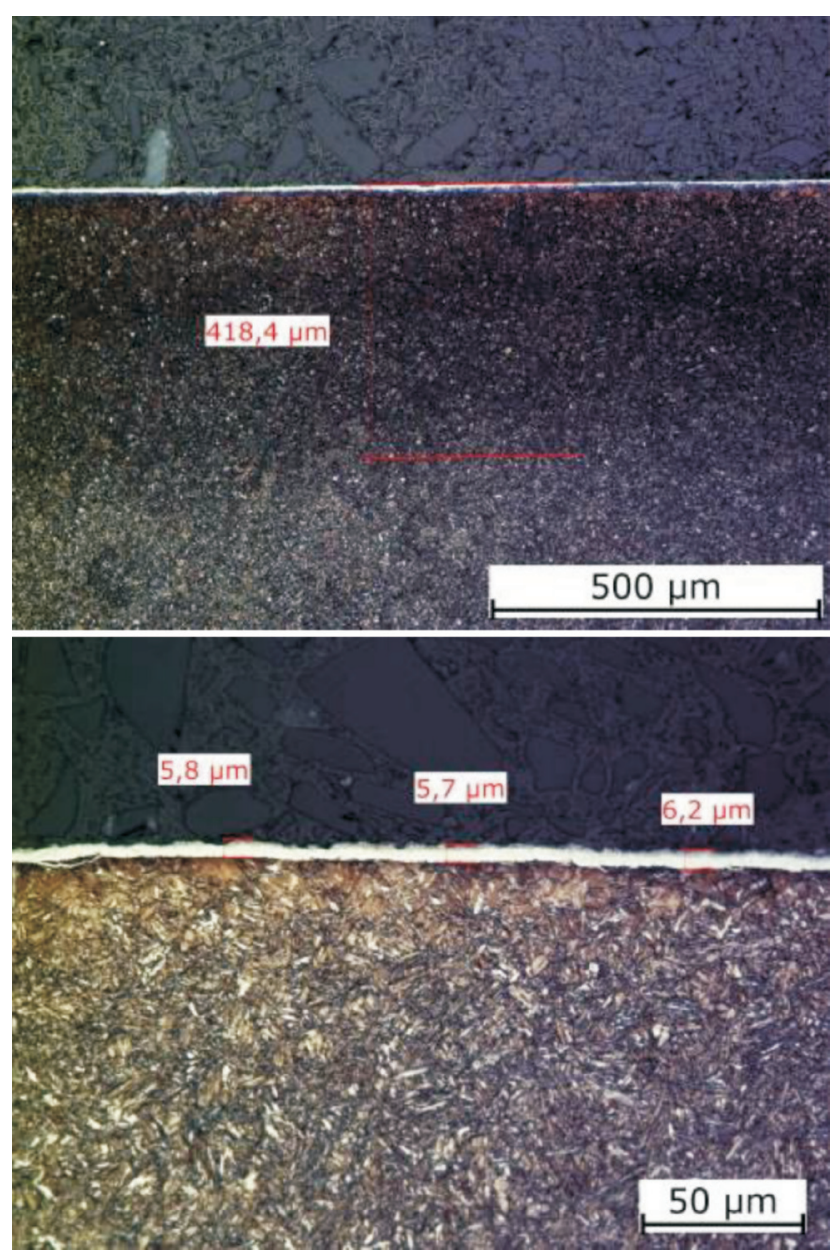

Fig. 6. Photomicrographs of the nitrided layer (left side) and iron nitrides (right side) obtained on 4340 steel during ZeroFlow nitriding

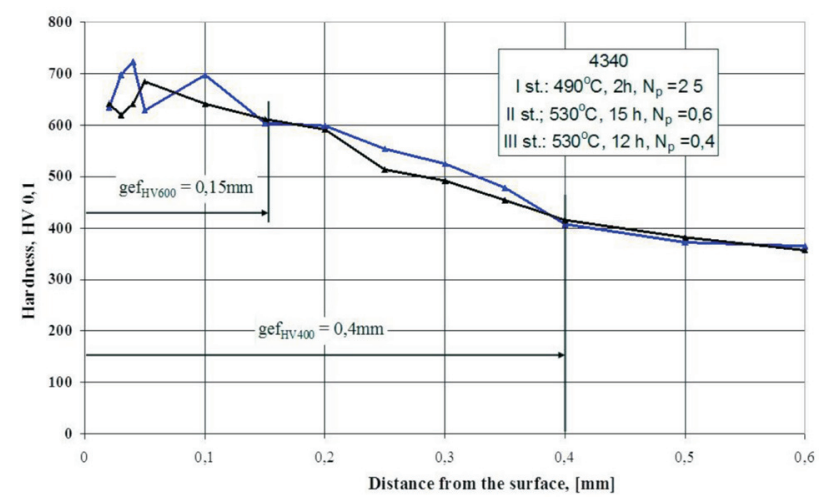

Fig. 7. Hardness distribution of nitrided layer obtained on 4340 steel during ZeroFlow nitriding

It is worth mentioning that during nitriding of crankshafts for sports car engines using ZeroFlow method total consumption of ammonia and emission of post-process gases 
was several times lower than during nitriding of the same crankshafts using traditional method (Fig. 8).

\section{Summary}

The example of nitriding of crankshafts for sports car engines shows that using simulation models, based on the kinetics of nitrided layer growth, it is possible to form nitrided layers precisely with respect to the required phase structure, zone thicknesses, and hardness distribution. Moreover, practical application of model enables the optimization of the process parameters, so the expected layers are obtained in the shortest possible time and with the lowest gases and energy consumption. Therefore, models (simulator) of the kinetics of nitrided layer growth support designing the nitriding processes and developing technology for new parts, and additionally they perform control and regulation functions.

The experimental and industrial experience gained so far not only confirmed the effectiveness and precision of ZeroFlow method, but they also confirmed the effectiveness of simulator as a supporting application. It means that ZeroFlow method can be successfully applied in nitriding of selected car engine parts, since it allows forming nitrided layers which fulfil the requirements imposed on them, andaccording to that - it allows to achieve appropriate durability of each part.

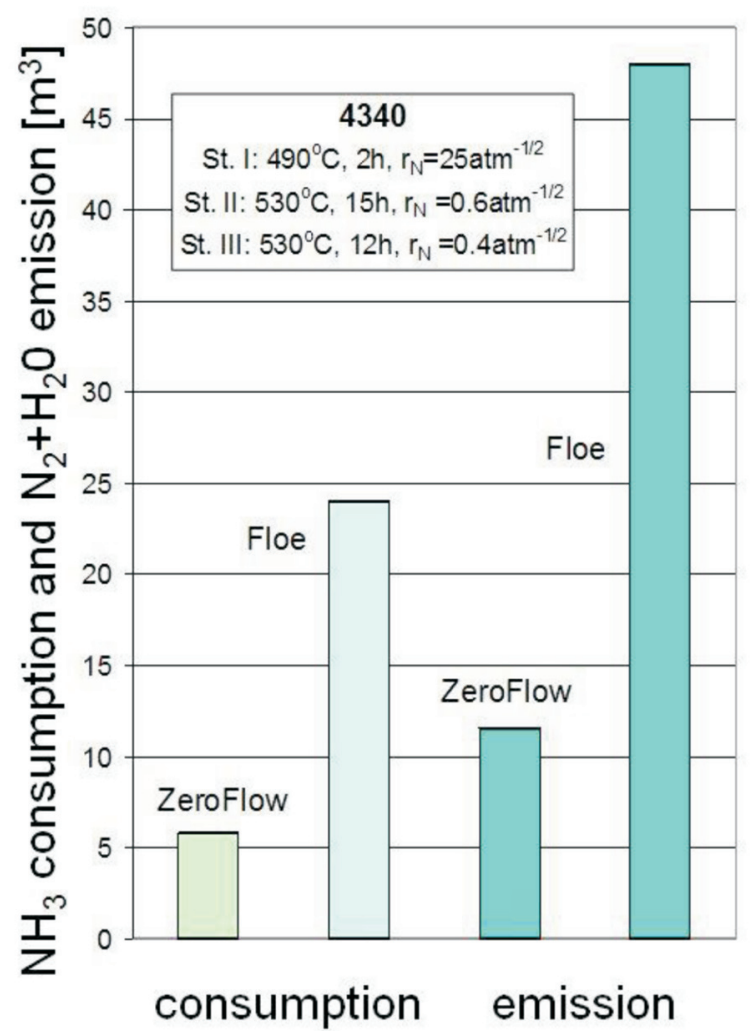

Fig. 8. Comparison of total amonnia consumption and post-process gases emission during nitriding of crankshafts in ZeroFlow and traditional process

\section{Bibliography}

[1] Campbell, F.C. Elements of metallurgy and engineering alloys, ASM International, Ohio, 2008.

[2] Kowalska, J. Regulacja i kontrola kinetyki wzrostu warstwy azotowanej na stalach w procesie regulowanego azotowania gazowego ZeroFlow. Badania i Rozwój Młodych Naukowców w Polsce. Nauki Techniczne i Inżynieryjne. Monografie 2015(12), Wyd. Młodzi Naukowcy, 120-126, Poznań 2015.

[3] Małdziński, L. Termodynamiczne, kinetyczne i technologiczne aspekty wytwarzania warstwy azotowanej na żelazie i stalach w procesach azotowania gazowego, Wyd. Politechniki Poznańskiej, Poznań 2002.

[4] Małdziński, L. Niskoemisyjne, ekonomiczne, regulowane azotowanie gazowe ZeroFlow, technologie zero-emisji. Ze- szyty Naukowe Politechniki Poznańskiej, Poznań 2011, pp. 189-229.

[5] Małdziński, L. Opracowanie symulatora kinetyki wzrostu warstwy azotowanej na stalach, report No. 6ZR8 2008 C/07141, unpublished, 2009

[6] Małdziński, L., Bazel, M., Korecki, M., Miliszewski, A., Przygoński, T. Controlled nitriding using a ZeroFlow method. Industrial experiences, Heat Treating Progress, July/August, 19-22, 2009.

[7] Pye, D. Practical nitriding and ferritic nitrocarburazing, ASM International, Ohio 2003.
Jagoda Kowalska, MEng. - postgraduate in the Faculty of Machines and Transport at Poznan University of Technology.

e-mail: jagoda.daria.kowalska@gmail.com

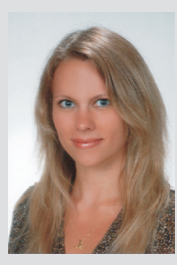

Prof. Leszek Małdziński, DSc, DEng. - Professor in the Faculty of Machines and Transport at Poznan University of Technology, Poland.

e-mail: leszek.maldzinski@put.poznan.pl 